\title{
Vitalum study design: RCT evaluating the efficacy of tailored print communication and telephone motivational interviewing on multiple health behaviors
}

\author{
Hilde $M$ van Keulen*1, Ilse Mesters ${ }^{1}$, Johannes Brug${ }^{2}$, Marlein Ausems ${ }^{1}$, \\ Marci Campbell ${ }^{3}$, Ken Resnicow ${ }^{4}$, Paul J Zwietering ${ }^{5}$, Gerard van Breukelen ${ }^{6}$, \\ Willem van Mechelen ${ }^{7}$, Johan L Severens ${ }^{8}$ and Hein de Vries ${ }^{1}$
}

Address: ${ }^{1}$ Department of Health Education and Health Promotion, School for Public Health and Primary Care (Caphri), Maastricht University, P.O. Box 616, 6200 MD Maastricht, The Netherlands, ${ }^{2}$ EMGO Institute, VU University Medical Centre, Van der Boechortstraat 7, 1081 BT Amsterdam, The Netherlands, ${ }^{3}$ Department of Nutrition, University of North Carolina at Chapel Hill, School of Public Health, 4102 McGravanGreenberg Hall, Chapel Hill, NC 27599-7461, USA, ${ }^{4}$ Faculty of Health Behavior and Health Education, University of Michigan, School of Public Health, 109 South Observatory, Ann Arbor, MI 48109-2029, USA, ${ }^{5}$ Department of General Practice, School for Public Health and Primary Care (Caphri), Maastricht University, P.O. Box 616, 6200 MD Maastricht, The Netherlands, ${ }^{6}$ Department of Methodology and Statistics, School for Public Health and Primary Care (Caphri), Maastricht University, P.O. Box 616, 6200 MD Maastricht, The Netherlands, ${ }^{7}$ Department of Public and Occupational Health, EMGO Institute, VU University Medical Centre, Van der Boechortstraat 7, 1081 BT Amsterdam, The Netherlands and ${ }^{8}$ Department of Health Organization, Policy, and Economics and Department of Clinical Epidemiology and Medical Technology Assessment, School for Public Health and Primary Care (Caphri), University Hospital Maastricht and Maastricht University, P.O. Box 616, 6200 MD Maastricht, The Netherlands

Email: Hilde M van Keulen* - h.vankeulen@gvo.unimaas.nl; Ilse Mesters - i.mesters@gvo.unimaas.nl; Johannes Brug - j.brug@vumc.nl; Marlein Ausems - marlein.ausems@av-m.nl; Marci Campbell - marci.campbell@unc.edu; Ken Resnicow - kresnic@umich.edu; Paul J Zwietering - paul.zwietering@hag.unimaas.nl; Gerard van Breukelen - gerard.vbreukelen@stat.unimaas.nl; Willem van Mechelen -w.vanmechelen@vumc.nl; Johan L Severens - h.severens@beoz.unimaas.nl; Hein de Vries - hein.devries@gvo.unimaas.nl

* Corresponding author

Published: 19 June 2008

BMC Public Health 2008, 8:216 doi:10.1 186/147|-2458-8-216
Received: 16 May 2008

Accepted: 19 June 2008

This article is available from: http://www.biomedcentral.com/I47I-2458/8/216

(C) 2008 van Keulen et al; licensee BioMed Central Ltd.

This is an Open Access article distributed under the terms of the Creative Commons Attribution License (http://creativecommons.org/licenses/by/2.0), which permits unrestricted use, distribution, and reproduction in any medium, provided the original work is properly cited.

\begin{abstract}
Background: A large proportion of adults fail to meet public health guidelines for physical activity as well as fruit, vegetable and fat intake. Interventions are needed to improve these health behaviors. Both computer tailoring and motivational interviewing have shown themselves to be promising techniques for health behavior change. The Vitalum project aims to compare the efficacy of these techniques in improving the health behaviors of adults aged 45-70. This paper describes the design of the Vitalum study.

Methods/Design: Dutch general medical practices $(N=23)$ were recruited via a registration network or by personal invitation. The participants were then enrolled through these general practices using an invitational letter. They $(n=2,88 \mathrm{I})$ received a written baseline questionnaire to assess health behaviors, and potential psychosocial and socio-demographic behavioral determinants. A power analysis indicated that 1,600 participants who were failing to meet the guidelines for physical activity and either fruit or vegetable consumption were needed. Eligible participants were stratified based on hypertension status and randomized into one of four intervention groups: tailored print communication, telephone motivational interviewing, combined, and control. The first two groups either received four letters or took part in four interviews, whereas the combined group received two letters and took part in two interviews in turns at 5 ,
\end{abstract}


13, 30 and 43 weeks after returning the baseline questionnaire. Each letter and interview focused on physical activity or nutrition behavior. The participants also took part in a telephone survey 25 weeks after baseline to gather new information for tailoring. There were two follow-up questionnaires, at 47 and 73 weeks after baseline, to measure short- and long-term effects. The control group received a tailored letter after the last posttest. The process, efficacy and costeffectiveness of the interventions will be examined by means of multilevel mixed regression, costeffectiveness analyses and process evaluation.

Discussion: The Vitalum study simultaneously evaluates the efficacy of tailored print communication and telephone motivational interviewing, and their combined use for multiple behaviors and people with different motivational stages and education levels. The results can be used by policymakers to contribute to evidence-based prevention of chronic diseases.

\section{Trial Registration: Dutch Trial Register NTRI068}

\section{Background}

Cardiovascular disease is a major cause of mortality throughout the world [1]. Both morbidity and mortality can be reduced by improving individuals' cardiovascular risk profile by, for example, preventing hypertension, lowering blood pressure in hypertensive people, increasing physical activity (PA) and fruit and vegetable consumption, and reducing saturated fat intake [1-9]. International public health guidelines have been developed for reducing the risk of cardiovascular diseases. Based on these, the Dutch guidelines recommend that Dutch people consume at least two pieces (approximately 200 grams) of fruit and 200 grams of vegetables a day, be moderately physically active at least 5 days a week for at least 30 minutes a day, and have a maximum saturated fat intake of $10 \%$ of their total energy intake $[1,7,10-15]$.

Various studies have shown that large percentages of adults fail to meet these public health recommendations [16-23]. De Vries and colleagues [23] showed that more than half of Dutch adults fail to meet the PA guideline, that $69.5 \%, 86.2 \%$ and $38.9 \%$ fail to meet the guidelines for fruit, vegetable and fat intake respectively and that only $3 \%$ adhere to all guidelines for PA, fruit, vegetable and fat intake, and smoking. Thus, interventions are needed to improve these health behaviors.

Computer tailoring and motivational interviewing (MI) are both innovative and promising intervention methodologies that are being used to improve health behaviors. Tailoring has been defined as "any combination of information or change strategies intended to reach one specific person, based on characteristics that are unique to that person, related to the outcome of interest, and have been derived from an individual assessment" (p. 1) [24]. Computers are useful tools to tailor messages for large groups of people at low costs [25]. Research has reported that computer tailoring has a positive effect on PA [26-30], fruit and vegetable consumption [26,31-38] and saturated fat intake $[39,40]$, also compared to generic information on changing these behaviors $[27,33,37,40,41]$.

MI is defined as "a client-centered, directive method for enhancing intrinsic motivation to change by exploring and resolving ambivalence" (p. 25) [42]. Evidence exists of the effectiveness of MI on PA [43-45], fruit and vegetable consumption [46-48] and saturated fat intake [49,50], and also when compared to standard advice on changing these behaviors $[45,47,48,50]$.

Research into tailoring emphasizes the need to compare these methods with others concerning their effects on changing behavior $[25,51]$. The Vitalum study contributes to this need. Its design was inspired by the NC STRIDES Project, which compared the effects of computer tailoring to those of MI in a colon cancer prevention and control study on PA and fruit and vegetable consumption in participants aged 50 or older [52-54]. Vitalum examines the efficacy of computer tailoring and MI on PA, fruit and vegetable consumption and saturated fat intake in participants aged 45 to 70 with and without hypertension. We also assess Vitalum's efficacy for different education levels since health disparities between SES groups are increasing [55] and health behavior adoption varies between these groups [56,57].

Older adults are an important target group for research and the development of lifestyle interventions for several reasons. First, adults between 45 and 70 represent more than $20 \%$ of the population in European countries [58]. Second, this percentage is likely to increase in the coming years [59]. Third, most blood pressure-related deaths or nonfatal events occur in middle age or in the elderly providing a cue to action for this age group [8]. Finally, older adults are important targets for prevention because health improvements due to increased PA, fruit and vegetable consumption, and lowered saturated fat intake still con- 
tribute to reduced risk of morbidity and mortality rates in this group $[1,7,60]$.

When Vitalum began in 2003 no results were available of studies that compared the economic consequences of interventions using computer tailoring and motivational interviewing. Physical inactivity, consuming too little fruit and vegetables and eating too much saturated fat may result in disease and loss of quality of life $[8,61]$. Therefore, Vitalum also aims to evaluate and compare the costeffectiveness of computer tailoring and motivational interviewing.

This article describes the Vitalum study design, which may help others in developing of equivalent interventions.

\section{Methods/Design \\ Participants and recruitment}

Vitalum was approved by the Medical Ethics Committee of Maastricht University and the University Hospital Maastricht, and is registered with the Dutch Trial Register (NTR1068).

In 2004 and 2005, Dutch general practices (GPs) from the southern Netherlands were invited to join in the recruitment of 1,600 participants via a registration network (Registration Network Family Practices; RNH) $[62,63]$ or by personal invitation. Twenty-three agreed to participate; 19 from the province of Limburg and 4 from Brabant. GPs that declined were participating in other research trials or had too little time.

Figure 1 shows the selection and enrollment of Vitalum participants. The population of the participating GPs consisted of 103,915 people, of whom $6,420(6 \%)$ were randomly selected to participate using five inclusion criteria: 1) aged $45-70 ; 2$ ) about $50 \%$ diagnosed by their GP as hypertensive according to the International Classification of Primary Care (ICPC) $[3,64,65]$ under ICPC code K86 or K87 in the GP database (i.e., hypertension without or with organ damage respectively); 3) about 50\% male; 4) not participating in other studies according to the GP database; and 5) maximum one person per address. To ensure participants' suitability for the study, they could be excluded ( $n=875,14 \%$ of the selection) by GPs before being invited. Exclusion was based on several criteria (see Figure 1), for example, having a "life-threatening or malignant disorder." After this exclusion, 5,545 eligible participants ( $86 \%$ of the selection) received an invitation from their GP to participate in Vitalum, in which the content of the study and group assignment was briefly explained. Those ( $n=2,341,36 \%$ of the selection) who did not respond received a reminder after four weeks. Ultimately, 4,379 people ( $68 \%$ of the selection) responded, of whom 2,881 (45\% of the selection) consented and 1,498 (23\% of the selection) refused to participate. Reasons for refusal included lack of time or interest. There was no response from $18 \%$ ( $n=1,166$ of the selection). Those who did agree to participate received a written baseline questionnaire, which was returned by 2,568 people $(89 \%$ of the consenters). Because it was logistically impossible to treat them all at the same time, participants were recruited and enrolled in 27 batches of maximum 200 participants. The duration between the first and last group to enroll and finish baseline data collection was 18 months (March 2005August 2006).

\section{Study design}

To ensure that we selected participants not satisfying the Dutch public health guidelines, people who returned the baseline questionnaire were included in Vitalum if they failed to meet at least two of these guidelines: PA and either fruit or vegetable consumption. Adequate saturated fat intake was not taken into account as an exclusion criterion, because most Dutch adults $(90 \%)$ fail to meet the guideline for this behavior [66]. Saturated fat intake received less attention in Vitalum than PA and fruit and vegetable consumption for a practical reason - to reduce the length of the tailored letters and motivational interviews.

Participants were stratified based on hypertension status prior to randomization. In total, 1,629 (63\%) of the 2,568 participants who filled out the baseline questionnaire were randomized in one of the four groups. A description of the study sample at baseline is shown in Table 1 . Because data of the selected people $(n=6,420)$ were only available at group level, attrition analyses were executed at group level for age, gender and hypertension status. Participants in the sample $(N=1,629)$ were compared with those who had been excluded or refused to participate (i.e., non-participants; $n=4,791$ ). These analyses revealed no significant differences in age between participants $(M$ $=57.15, S D=7.13)$ and non-participants $(M=57.02, S D$ $=7.38 ; t(6,418)=0.62, p>.05)$, nor for gender, $\left(\chi^{2}(1, n=\right.$ $6,420)=1.92, p>.05)$. However, participants $(52 \%$ with and $48 \%$ without hypertension) were more likely to suffer from hypertension than were non-participants (49\% with and $51 \%$ without hypertension; $\chi^{2}(1, n=6,420)=4.53, p$ $<.05)$.

Participants were stratified and randomized into the following four groups by a computer program.

1. The tailored print communication (TPC) group, in which participants received four tailored letters. The first and third letter focused on PA, the second and fourth on fruit and vegetable consumption, and the fourth also addressed fat intake. 


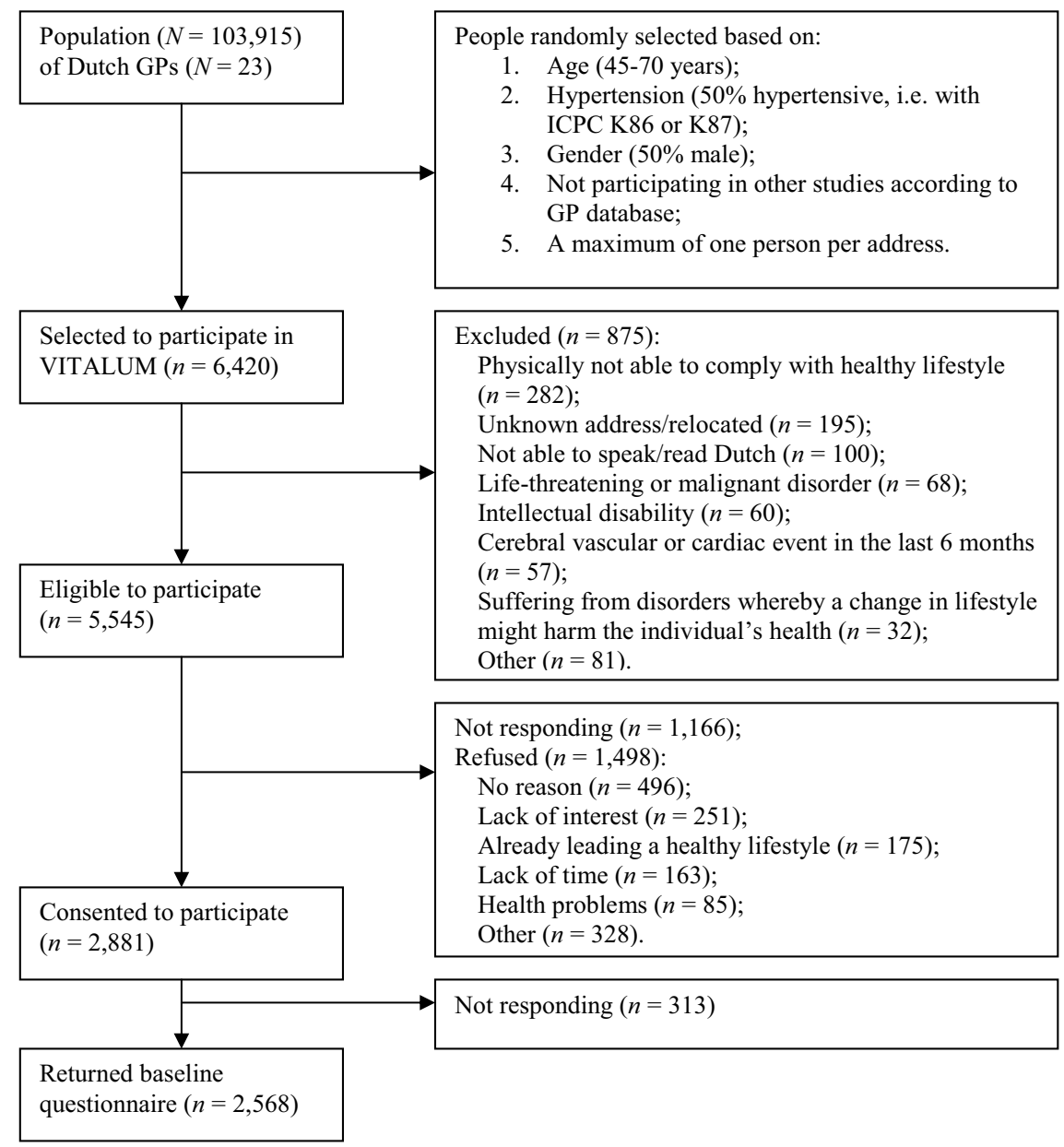

Figure I

Flow diagram of the selection and enrollment of Vitalum participants.

2. The telephone motivational interviewing (TMI) group, in which participants received four telephone calls based on MI. Participants chose the order of the conversation topics in the first and third call. If they chose to focus on PA in the first call, fruit and vegetable consumption was discussed in the second, and vice versa; they could also choose to discuss fat intake in the fourth call.

3. The combined group (TPC+TMI), in which participants received two tailored print letters and two telephone motivational interviews in turns. The first letter and call addressed PA; the second letter and call focused on fruit and vegetable consumption. Participants could also choose to discuss fat intake in the fourth call. The total number of intervention components (4) was kept to a similar total number as that of the first two groups. Also, we exposed participants to an equal amount of each intervention type $(2 * \mathrm{TPC}, 2 * \mathrm{TMI})$ to keep the influence of both methods as comparable as possible.
4. The control group, in which participants received one tailored letter based on the last follow-up questionnaire.

Participants from the three intervention groups received their four intervention components at 5, 13, 30 and 43 weeks after they had returned the baseline questionnaire. This timeframe was chosen to spread delivery of the components throughout the year [48]. Vitalum used a twoway design (TMI * TPC) except for the fact that the combined group received half of each treatment type $(2 *$ TPC and $2{ }^{*}$ TMI instead of $4 *$ TMI and $4{ }^{*}$ TPC). The study design and timeline is depicted in Figure 2.

Participants' behaviors and determinants were assessed by an intermediate telephone survey after two intervention components, 25 weeks after returning the baseline questionnaire, to gather the most recent information for the computer tailoring intervention. This survey also assessed the effects of the intervention. In addition, participants in 
Table I: Vitalum sample description $(N=1,629)$

\begin{tabular}{|c|c|}
\hline & \%/Mean, SD (range) \\
\hline \multicolumn{2}{|l|}{ Gender } \\
\hline$\%$ male & 55 \\
\hline Age & 57.1, $7.1(44.9-70.9)$ \\
\hline \multicolumn{2}{|l|}{ Native country } \\
\hline$\%$ the Netherlands & 95 \\
\hline \multicolumn{2}{|l|}{ Education level* } \\
\hline$\%$ low & 54 \\
\hline$\%$ intermediate & 23 \\
\hline$\%$ high & 23 \\
\hline \multicolumn{2}{|l|}{ Hypertension } \\
\hline$\%$ Hypertensive & 52 \\
\hline Body Mass Index & $27.4,4.6(15.2-46.7)$ \\
\hline$\%<18.5$ & I \\
\hline$\% 18.5-25$ & 31 \\
\hline$\% 25-30$ & 45 \\
\hline$\%>=30$ & 22 \\
\hline \multicolumn{2}{|l|}{ Smoking behavior } \\
\hline$\%$ nonsmokers & 78 \\
\hline \multicolumn{2}{|l|}{ Alcohol consumption** } \\
\hline Glasses/day & I.I, I.4 (0-9) \\
\hline$\%$ meeting guideline & 86 \\
\hline \multicolumn{2}{|l|}{ Saturated fat intake } \\
\hline Fat score & $17.8,5.9(2-37)$ \\
\hline$\%$ meeting guideline & 30 \\
\hline \multicolumn{2}{|l|}{ PA } \\
\hline Hours/week moderately physically active & $4.7,3.8(0-20.2)$ \\
\hline $\begin{array}{l}\%>=2.5 \text { hours/week moderately } \\
\text { physically active }\end{array}$ & 61 \\
\hline Days/week moderately physically active & $2.2,1.6(0-7)$ \\
\hline $\begin{array}{l}\%>=5 \text { days/week moderately physically } \\
\text { active }\end{array}$ & 6 \\
\hline$\%$ meeting guideline combined & 0 \\
\hline \multicolumn{2}{|l|}{ Fruit consumption } \\
\hline Pieces of fruit/day & 2.1, I.6 (0-8.9) \\
\hline$\%>=2$ pieces/day & 41 \\
\hline Days/week at least 2 pieces/day & $3,2.5(0-7)$ \\
\hline$\%>=7$ days/week at least 2 pieces/day & 13 \\
\hline$\%$ meeting guideline combined & 11 \\
\hline \multicolumn{2}{|l|}{ Vegetable consumption } \\
\hline Grams of vegetables/day & $165.2,82.4(0-494.7)$ \\
\hline$\%>=200$ grams $/$ day & 31 \\
\hline Days/week at least 200 grams/day & $4.1,2.0(0-7)$ \\
\hline$\%>=7$ days/week at least 200 grams/day & 11 \\
\hline$\%$ meeting guideline combined & 7 \\
\hline
\end{tabular}

* Education level was classified as: low in participants with no education, primary, lower secondary vocational, preparatory vocational or junior general secondary education; intermediate in participants with senior secondary vocational, technical secondary, upper vocational secondary, senior general secondary or university preparatory education; and high in participants with higher professional or university education [125-127].

** Participants were classified as meeting the alcohol consumption guideline if they consumed fewer than 3 glasses a day (men) or fewer than 2 glasses a day (women) [10].

the TPC group were telephoned 39 weeks after returning the baseline questionnaire, again to collect the most recent data on behavior and its determinants. Interven- tion effects were assessed by two follow-up paper questionnaires, 47 and 73 weeks after the baseline questionnaire. Two reminders were sent to participants who failed to respond at baseline and both follow-ups; a postcard after 3 weeks and a letter including the questionnaire after 6 weeks. For the telephone surveys 25 and 39 weeks after baseline, 4 and 3 weeks respectively were used to contact participants and carry out the survey.

Participants received a pedometer as a reward for their participation, with short instructions encouraging them to gradually increase their number of steps to at least 10,000 a day [67]. By rewarding participants, we were also able to assess the effect of this reward on their physical activity levels. Therefore, half the participants in the TPC, TMI and TPC+TMI groups received their reward before the third intervention component (29 weeks after returning the baseline questionnaire); the remainder received the reward after the last follow-up. Participants were stratified on hypertension status prior to randomization in two groups (receiving a pedometer during or after the study). In the first follow-up questionnaire, 47 weeks after returning the baseline questionnaire, all participants were asked if they owned and used a pedometer. We were thus able, first, to study intervention effects via the telephone questionnaire after two intervention components, and second, to study the effect of the pedometer reward on participants' physical activity levels. This aspect was later treated as an independent variable in the analyses.

\section{Intervention materials}

\section{Tailored print communication (TPC)}

The message content and message algorithms of the TPCs were based on prior effective theory-based computer-tailored interventions on PA and fat, fruit and vegetable intake developed by Brug et al. [33], Oenema et al. [37] and Smeets et al. $[30,68]$ and on focus group interviews held with people from the target population. An important addition was that Vitalum's tailored messages were based on more items and feedback was item-specific (instead of scale-based, as in the previous studies) to further personalize and tailor the feedback. This level of tailoring was also chosen to make TPC more comparable with TMI, given that in TMI the counselor can tailor the conversation to determinants mentioned by the participant (e.g., specific advantages of PA).

The computer-tailored interventions were based on the integrated model for exploring motivational and behavioral change (I-Change Model) [69-71]. The I-Change Model states that behavior is determined by people's motivation or intention to perform a certain behavior. Barriers can decrease the chance that intentions will result in action. Individuals' abilities, such as being able to plan specific actions to reach the target behavior (i.e., action 
Timeline in weeks:

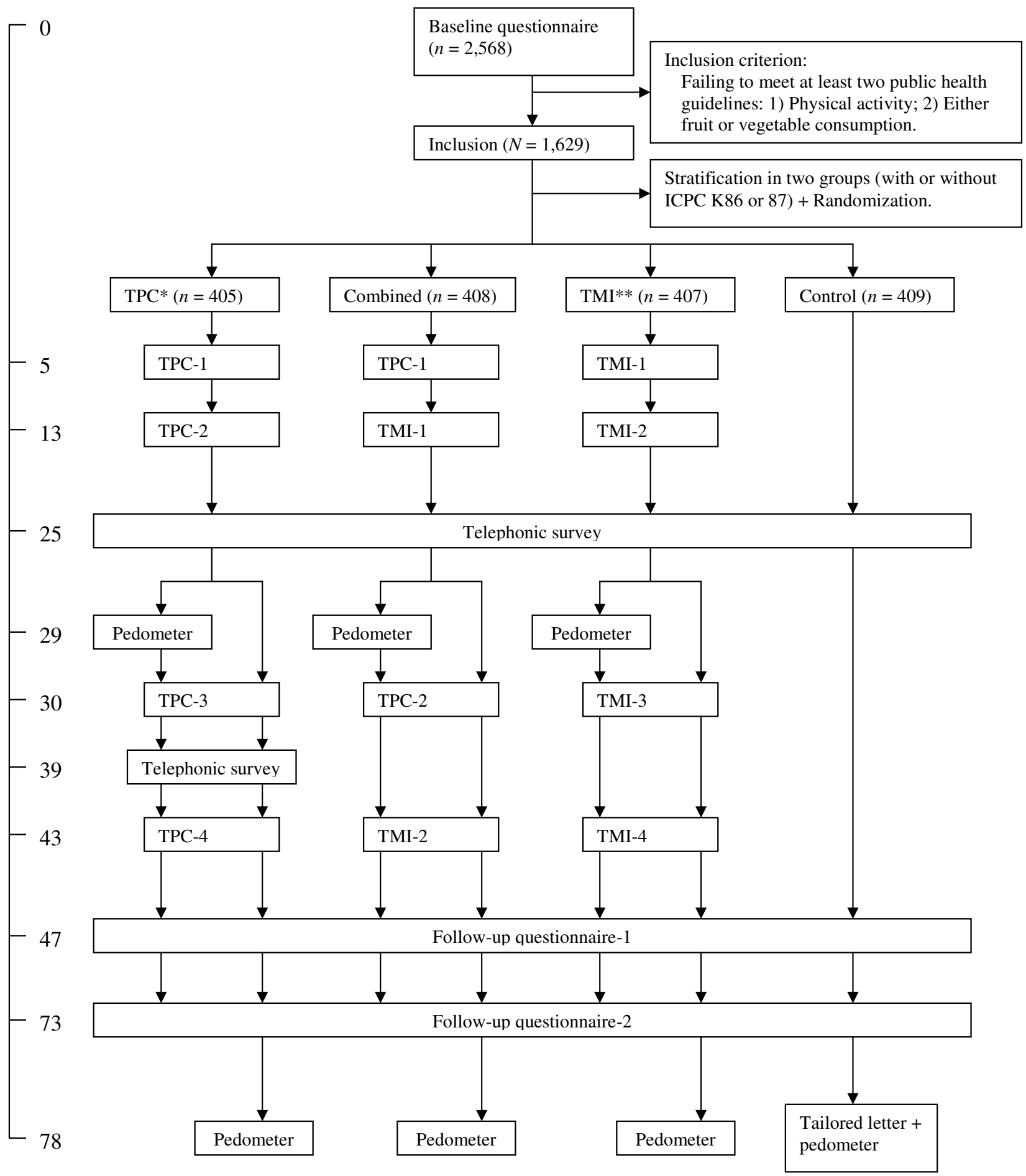

Figure 2

Design and timeline of Vitalum. $*$ TPC $=$ Tailored print communication. $* *$ TMI $=$ Telephone motivational interviewing. 
plans), can increase the chance that intentions will result in action. Motivation factors, like attitudes, social influences and self-efficacy expectations determine a person's intention to change. These motivation factors are influenced by (a) awareness factors, such as knowledge; (b) information factors, such as message quality; and (c) predisposing factors, namely behavioral, psychological, biological and social and cultural factors. Behavioral determinants according to the I-Change Model were measured and used to tailor the information in the letters. The I-Change Model, in line with the Transtheoretical Model [72], posits that individuals can move forward and backward through different motivational phases towards behavior change. Precontemplators are people who do not plan to change their behavior in the next six months; contemplators do intend to change their behavior in the next six months; preparators plan to change their behavior in the next month; actors have changed their behavior in the past six months; and maintainers have maintained their changed behavior for longer than six months. Consequently, Vitalum participants received stage-matched advice [72-74], based on the Transtheoretical Model stages of change algorithm [72]. Tailoring variables were current behavior according to validated questionnaire, self-rated behavior, stage of change, attitude, self-efficacy expectations, awareness, action plans, age and gender.

The letters, TPC1 and TPC2 (each 3-6 pages), were personalized with the participant's name and provided with the following tailored elements:

1. Introduction, explaining the purpose of Vitalum and what to expect from the letter.

2. Specific behavioral feedback about targeted behavior, in order to stimulate self-regulation in line with Carver and Scheier's [75] behavioral self-regulation model, including current behavior compared to: (a) the public health recommendation, (b) participants' estimation, and (c) others of the same age.

3. Stage-matched advice to change behavior: (a) participants without plans to change their behavior received tailored feedback on the advantages of change; (b) precontemplators received feedback on advantages and disadvantages of change; (c) contemplators received feedback on advantages, disadvantages and action plans; (d) preparators received feedback on self-efficacy expectations and action plans; and finally (e) actors and maintainers received tailored feedback on action plans.

4. Conclusions and preview of the next letter.
An example of such stage-matched advice is shown in the appendix; a summary of the elements in a TPC can be found in Figure 3.

Subsequent letters, TPC3 (2-4 pages) and TPC4 (4-6 pages), reinforced tailored feedback on behavioral progress and stages of change, and used similar strategies to those mentioned above. Information on saturated fat intake only addressed behavior rather than stages of change, to reduce the length of the fourth letter. The tailored letters for participants in the combined group took the same format as those described above. The message algorithm and messages were examined by an expert before implementation. The letters were computer generated, mailed to participants' home addresses and signed by the principal researchers (authors IM, MA and HMvK).

\section{Telephone motivational interviewing (TMI)}

In Vitalum, motivational interviewers were trained by two certified trainers during six 3-hour sessions. Eligible interviewers were bachelor's and master's students of Health Education and Health Promotion, Mental Health Sciences or Psychology at Maastricht University. Though these students were being educated in health sciences disciplines, they had not yet developed counseling routines and were therefore expected to be easier to train in MI skills than experienced counselors; they would not have to unlearn or replace counseling habits with new ones. In total, 53 students were trained in four separate groups. At the end of the training they performed one TMI guided by a Vitalum interview protocol. All calls were tape-recorded and assessed by two raters with the 1-PASS [76], a tool to measure MI intervention fidelity. The general conclusion was that they performed very well; both the training and the interview protocol guaranteed good quality performance. Those who had a $100 \%$ attendance and an adequate score on the MI qualities were then able to apply for a contract to work as a Vitalum motivational interviewer. Sixteen applicants were contracted.

To assist the interviewers in applying MI, an interview protocol was developed and used for each interview in the intervention groups. The protocols were based on those used by Resnicow et al. in the Healthy Body Healthy Spirit trial $[47,77]$ and were pretested with experts and representatives from the study population. The protocols followed the basic steps of MI outlined by Miller and Rollnick [42]. Each protocol included the following elements:

1. Introduce self and build rapport - the interviewer introduces him/herself, explains the reason for the call, and asks if it is okay to continue. 


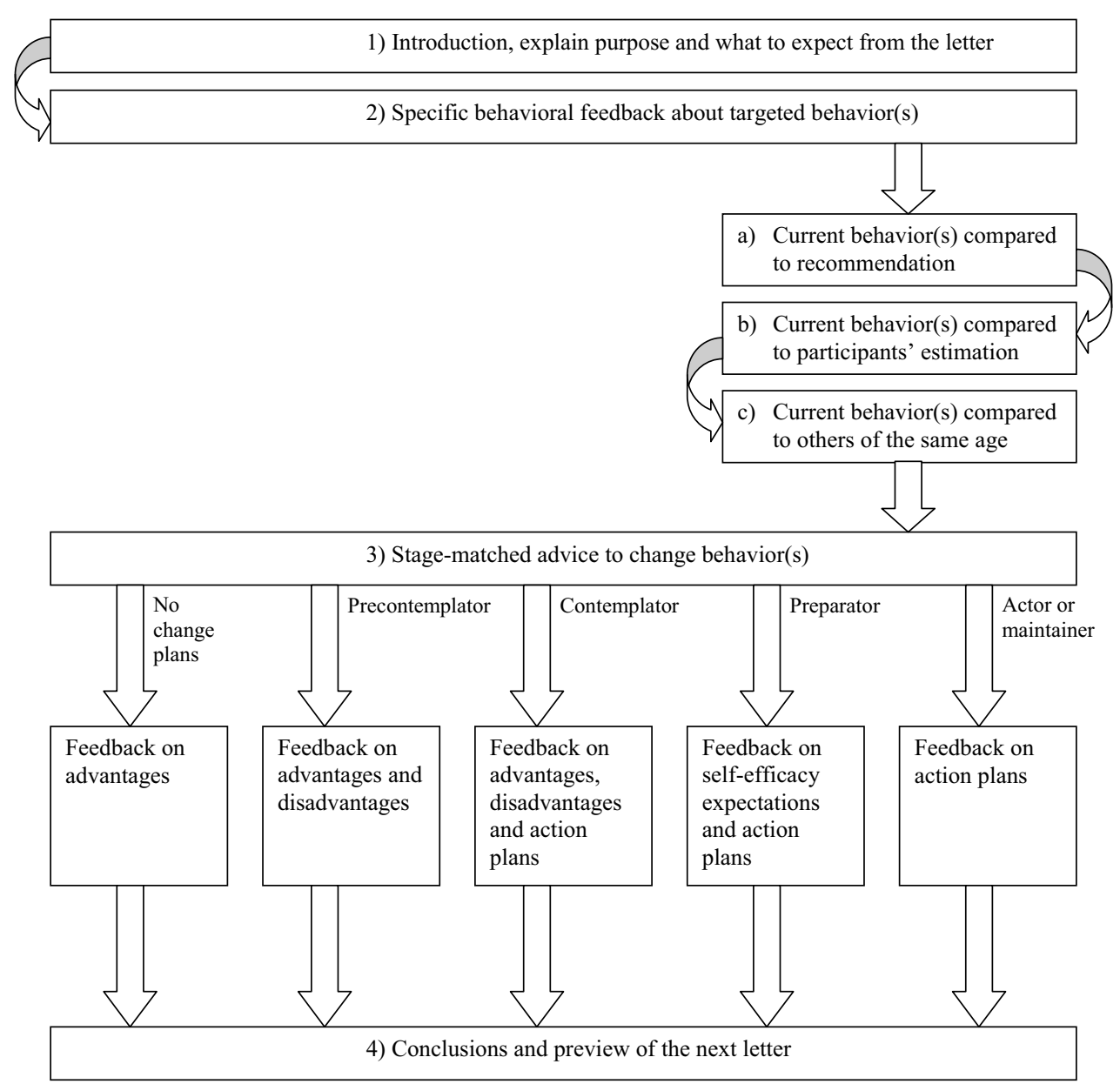

Figure 3

Tailored print communication elements.

2. Assess current behaviors and progress - the interviewer summarizes the participants' behavior based on a participant profile generated from the questionnaire or survey and checks whether this profile fits their current behavior.

3. Discuss the public health guideline of a certain behavior in relation to the participant's current behavior.

4. Assess and enhance motivation and self-efficacy for behavior change with the importance and confidence ruler as described by Resnicow et al. [77] and Miller and Rollnick [42] and developed by Rollnick [78]. Importance and confidence were examined subsequently in four steps: (a) assess importance and confidence with ruler, (b) ask "Why did you not choose a lower number?", (c) ask "Why did you not choose a higher number?", and (d) ask "What would it take for you to reach a higher number?".
5. Assess readiness to change. For those ready to change (a) brainstorm possible actions, (b) facilitate commitment to change and goal setting, (c) explore barriers or concerns and brainstorm solutions. For those not ready to change (a) explore lack of interest or ambivalence, and (b) encourage participant to think about change.

6. Summarize interview and ask for feedback on summary.

7. Explain when the next call can be expected and close the session.

The elements included in the interview protocol are summarized in Figure 4.

The protocols of the second, third and fourth interviews in the TMI group and of the second interview in the com- 


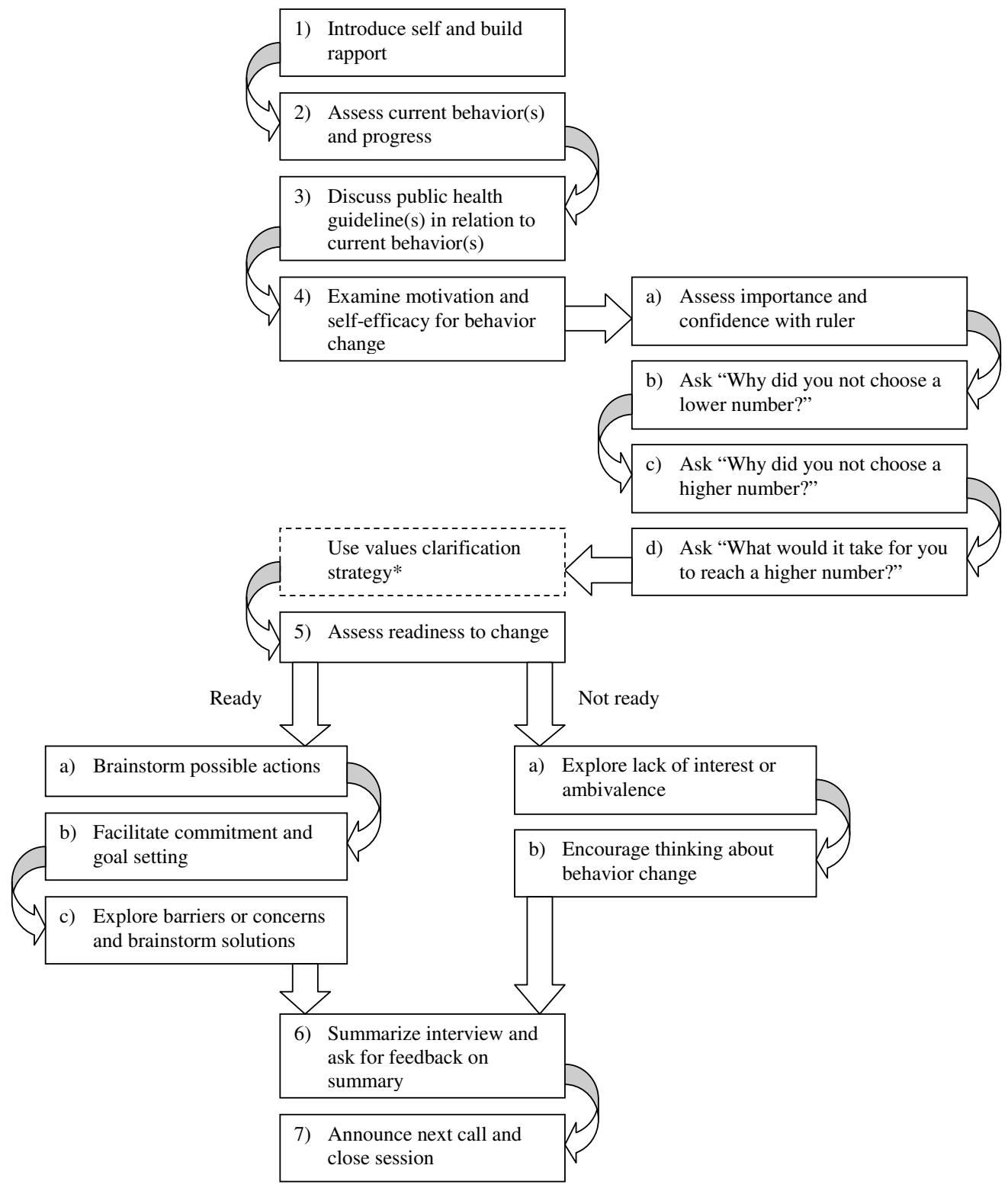

Figure 4

Telephone motivational interviewing protocol elements. * Only in the third interview protocol of the TMI group and second interview protocol of the combined group

bined group contained an extra element after the introduction: Discuss progress on action plans, if plans were made, and discuss the current situation, if participants had no plans to change. This extra element was added to help participants make progress in changing their behavior or thinking about behavioral change. The interview protocols of the combined group contained an extra topic after the introduction: Discuss the tailored letter. The third protocol of the TMI group and the second of the combined group also contained the possibility for the inter- viewers to use the values clarification strategy described by Resnicow et al. [77].

Besides the interview protocols, interviewers received general information about cardiovascular diseases, hypertension and the specific health behaviors (physical activity, fruit and vegetable consumption and fat intake), and an MI-Change Talk card on which methods to evoke and strengthen change talk and confidence talk were summarized as described by Miller and Rollnick [42]. 
The TMIs were expected to take on average 20 minutes. The interviewers wrote a summary of each interview to assist in the next interview. Interviewers were scheduled to interview the same participants as far as possible; however, due to job transfers and availability, this was not always possible. To assess the interviewers' competence in the use of MI, the interviews were computer recorded. A random 20-minute segment of a random sample of $20 \%$ of the interviews will be coded, $20 \%$ of these ( $4 \%$ of all interviews) will be examined by two trained coders for inter-coder reliability with the use of the Motivational Interviewing Treatment Integrity (MITI 3.0) code [79,80] and the 1-PASS Coding System for Motivational Interviewing (1-PASS) [76]. The MITI 3.0 consists of two components: global scores and behavior counts. The global scores of empathy, MI spirit (evocation, collaboration and autonomy support) and direction capture an overall impression of the interview ( $1=$ poor, to $5=$ ideal $)$, whereas the behavior counts examine specific interviewer behavior; the number of open and closed questions, simple and complex reflections, the provision of information, and MI adherent and non-adherent utterances. Recommended competency thresholds as described in the MITI $3.0[80,81]$ will be used to determine interviewer competency for the behavior counts as well as the global scores. The 1-PASS consists of 16 items $(1=$ poor/never to $7=$ excellent/always) that measure, for example, whether the interviewer effectively uses the importance ruler or values clarification strategy. The average 1-PASS score is calculated by dividing the sum of the items by the number of applicable items. As described in the 1-PASS manual, an average score of 5 is regarded as sufficient [76].

\section{Tailored print communication versus telephone motivational interviewing}

Because TPC and TMI are different methods, they are also expected to have different effects. The first reason for this stems from their media differences. TPC is print-based and essentially a passive, one-way form of communication. It is therefore assumed to have less impact on people with a lower education level [25], whereas TMI is more interactive and assumed to be more effective for these people. The second reason concerns individuals' motivation to change behaviors. The Protection Motivation Theory $[82,83]$ states that people can be motivated to protect their health by two processes: threat appraisal and coping appraisal. Threat appraisal is influenced by individuals' perceived seriousness of the situation and their susceptibility. A higher perceived threat may lead to more motivation to protect oneself. In line with Protection Motivation Theory, people without hypertension are assumed to have less interest in and motivation to change than people with hypertension. Since people less ready to change may benefit more from motivation-enhancing interventions $[48,84,85]$ it is possible, therefore, that people without hypertension will benefit more from TMI, because they may be more ambivalent and less ready to follow advice than people with hypertension. The largest effect is anticipated for the combined (TPC+TMI) group, as we assume that the positive aspects of both TPC and TMI will be reinforced in this group.

\section{Hypotheses}

Effect size estimates for our intervention and control conditions were difficult to determine, because similar studies were not available at the start of Vitalum (2003). However, one study on MI [48] and others on computer tailoring $[27,33,40]$ found increases of at least $10 \%$ in one or more of the target behaviors (i.e., PA, fruit or vegetable consumption, or saturated fat intake) in participants who received single or multiple $\mathrm{MI}$ or tailoring compared to control group participants. As PA and fruit and vegetable consumption will receive more attention than saturated fat intake, we also expect to find larger effects for these. Therefore, we formulated the following hypotheses:

1. Compared to those in the control group, participants receiving either TMI or TPC will (a) increase PA as well as fruit and vegetable intake by $10 \%$ at the first follow-up from the expected mean at baseline; and (b) decrease saturated fat intake by $5 \%$.

2. Participants receiving TPC+TMI will have resulting behavioral changes which exceed the sum of the changes expected given each intervention.

3. Participants with a low education level benefit more from TMI than TPC.

4. Participants without hypertension benefit more from TMI than TPC.

\section{Outcome measures}

\section{Primary outcome measures}

To measure the efficacy of TPC, TMI and TMI+TPC, the primary outcome measures of Vitalum were PA, fruit and vegetable consumption and whether participants adhered to public health guidelines with regard to these behaviors. These were measured at baseline, the intermediate telephone survey and both follow-ups $(25,47$ and 73 weeks after baseline respectively). Since PA and fruit and vegetable consumption receive more attention in Vitalum, saturated fat intake was seen as a secondary outcome measure. Other studies showed that multiple-item measurements may result in people overestimating their behavior [8695] and that adjusting the results of a multiple-item measurement with those of a single-item measurement let to reduced overestimation $[86-88,92,93]$. Therefore, the primary outcome measures are single - as well as multiple- 
item measurements, and both are combined into a measure as described below to reduce overestimation.

\section{Physical activity (PA): single-item measurement}

PA was assessed using one item, the final question of the Short Questionnaire to Assess Health-enhancing physical activity (SQUASH) [96]: "How many days a week do you cycle, engage in do-it-yourself (DIY) activities, do gardening, play a sport or engage in other strenuous physical activities for at least 30 minutes a day?" The SQUASH has been validated with an accelerometer (CSA activity monitor, $\left.r_{\text {spearman }}=.45, p<.01\right)$. In terms of the single-item adherence measurement, participants were classified as adhering to the Dutch PA guideline if their answer to this question was 5 or more days $[7,11,13]$.

\section{Multiple-item measurement}

PA was also measured using 28 items from the modified CHAMPS physical activity questionnaire [97], which assesses the frequency of an activity (times per week) and its duration (hours per week). This questionnaire has been validated with cardiorespiratory fitness $\left(\mathrm{VO}_{2}\right.$ maximum) estimated by a submaximal treadmill test $\left(r_{\text {pearson }}=\right.$ $.17, p<.05)$ [97]. Activities that were measured included: walking leisurely; walking fast or briskly; cycling leisurely; cycling fast or briskly; doing light gardening; doing heavy gardening; doing light housekeeping; doing heavy housekeeping; jogging or running; swimming; playing tennis, table tennis or badminton; playing a team sport indoors or outdoors; doing light exercises to maintain a physical condition, for example, stretching or flexibility exercises; and doing heavy exercises, for example aerobics, fitness or strength training. Metabolic equivalents (METs) were determined for each activity on the basis of the PA compendium by Ainsworth et al. [98]. MET levels were used as cut-offs to calculate the total number of weekly PA hours with at least a moderate intensity. Only activities with at least four METs were considered moderate for participants younger than 55, and activities with at least three METs considered moderate for participants aged 55 and older [11]. In terms of multiple-item adherence measurement, participants were classified as adhering to the PA guideline if they were physically active with at least moderate intensity for at least 2.5 hours a week.

\section{Combined measure}

Multiple- and single-item measurements were also recoded into a combined measure to classify adherence: participants were only coded as "meeting the PA guideline" if they did so according to both the multiple- and single-item measurements.

\section{Fruit and vegetable consumption: single-item measurement}

Both fruit and vegetable consumption were assessed using single-item measurements: one for fruit ("How many days a week do you eat at least two pieces of fruit?") and one for vegetables ("How many days a week do you eat at least $200 \mathrm{~g}$ of vegetables?"). In terms of the single-item adherence measurement, participants were classified as adhering to the guideline for fruit and vegetable consumption if their answer to both these questions was 7 days [10].

\section{Multiple-item measurement}

Fruit and vegetable consumption was also measured using 16 items from the short questionnaire for fruit and vegetable intake [99]. The questionnaire has been validated with blood levels of carotenoids $\left(r_{\text {spearman }}=.39, p<.001\right.$ for fruit; $r_{\text {spearman }}=.24, p<.001$ for vegetables) and vitamin $\mathrm{C}\left(r_{\text {spearman }}=.37, p<.001\right.$ for fruit; $r_{\text {spearman }}=.26, p<.001$ for vegetables) [99]. This questionnaire measured frequency (days per week) and quantity (pieces/serving spoons per day) of vegetables (cooked and raw) and fruit (fruit juice, citrus fruits, tangerines, apples or pears, bananas and other fruits). Two tangerines were considered one piece of fruit. Frequency and quantity were used to determine daily consumption. In terms of the multipleitem adherence measurement, participants adhered to the fruit consumption guideline if they consumed at least two pieces (two servings) a day, and to the vegetable consumption guideline if they consumed at least $200 \mathrm{~g}$ (4 serving spoons) a day [10].

\section{Combined measure}

Multiple- and single-item measurements were recoded into a combined measure to classify adherence: participants were only coded as "meeting the fruit guideline" if they did so according to multiple- and single-item measurements. The same applied for vegetable consumption.

\section{Secondary outcome measures}

Secondary outcomes include saturated fat intake, healthrelated quality of life, body mass index (BMI) and cognitive behavioral determinants. Except the latter, these were measured at baseline and both follow-ups (43 and 73 weeks after baseline). Cognitive determinants of primary behavioral outcomes were also measured at the first telephone survey (25 weeks after baseline); but because Vitalum's main focus was to measure behavior change, cognitive behavioral determinants of all outcomes except for intention - were not measured at the second follow-up (73 weeks after baseline). This also reduced the length of the second follow-up questionnaire, thereby possibly reducing dropout.

Saturated fat intake was measured using a 35-item short food frequency questionnaire, the Fat list [100]. The list has been validated with a 7 -day diet record $\left(r_{\text {pearson }}=.69\right.$ for saturated fat intake, $p$ not reported) [100]. Saturated fat intake was assessed using questions about frequency and quantity of 19 food items (dairy products, bread 
spreads, cheese, meat, gravy, savory snacks and sweet snacks). Frequency, quantity and item type were used to calculate a total fat score for the 19 items $(0-5$ points per item). One fat point represents about $2 \mathrm{~g}$ of saturated fat intake. Respondents were classified as adhering to the guideline for saturated fat intake depending on gender: men with a total fat score of 15 or less and women with 13 or less [100].

Health-related quality of life was measured with the RAND 36-item Health Survey $1.0[101,102]$ which measures individuals' physical and social functioning, role limitations due to physical or emotional problems, mental health, pain, general health perception and health change.

$B M I$ was calculated from self-reported body weight and height $\left(\mathrm{kg} / \mathrm{m}^{2}\right)$.

Cognitive behavioral determinants were measured using variables that represent the I-Change Model [69-71]. Behavioral determinants were measured for each behavior, fruit and vegetable consumption separately, and included stages of change [103,104], attitudes [30], social influence [30], self-efficacy expectations [105], ability factors (i.e., action plans) [106], habit [107], and awareness based on self-rated behavior and the assessment of behavior by questionnaire $[108,109]$. These questions were also based on previous questionnaires (see references for each construct) as well as unpublished results of focus group interviews with people from the study population. The baseline questionnaire was piloted for comprehension and conceptual salience with representatives of the study population.

\section{Socio-demographic variables}

Socio-demographic variables that were measured included highest completed level of education, marital status, work situation, native country, presence of diabetes, smoking behavior $[73,110]$, alcohol consumption [111], family history of cardiovascular disease, and stress [112]. In addition, the Physical Activity Readiness Questionnaire (PAR-Q [113]) was used to assess barriers to participation in physical activity, for example, chest pain during physical activity or bone or joint problems.

Gender, hypertension status and age were used as variables for selecting participants from the GP database and these data were provided by the GP only when participants agreed to participate. The other socio-demographic variables were measured at baseline; smoking behavior and alcohol consumption were also measured at both follow-ups (47 and 73 weeks after baseline).

\section{Statistical analyses}

\section{Sample size and power}

The required sample size was determined using the formula for unpaired $t$-tests [114], as each effect test in a balanced $2 \times 2$ between-subject design (i.e., the TMI and the TPC main effects and their interaction) comes down to such $t$-tests (apart from having less residual variance). The sample size calculation was based on the following assumptions: (a) since results of similar studies were not available at the start of Vitalum, the sample size calculation was based on a small expected effect size (Cohen's d) of .3 [115]; (b) a power of .9; (c) an alpha of .01 to correct for multiple testing; (d) an intra class correlation of .02, where the correlation is based on random treatment by GP interaction (a random GP main effect does not affect the sample size in the event of person randomizations within GPs) [116]; and (e) an expected average number of participants per general practice of 70 . Loss of power due to random dropout or a gain in power from including the pretest as a covariate in the analyses [117] was not taken into account in the sample size calculation. However, the loss of power due to $20 \%$ random dropout can be compensated by including the pretest as a covariate if it correlates .5 with the posttest - the latter correlation being a realistic assumption. These assumptions resulted in a required sample size at baseline of 1,600. Thus, Vitalum aims to assess 400 participants per group at baseline. Assuming $50 \%$ of people refuse participation, and $40 \%$ of the remaining group meet the recommendations for PA and nutrition and are thus excluded, at least 5,400 people must be invited to secure 1,600 for the study.

\section{Primary and secondary outcome analyses}

Primary and secondary outcome measures will be used in the primary and secondary outcome analyses respectively. Vitalum's short-(week 47) and long-(week 73) term results will be analyzed with a 3-level multilevel mixed regression using Statistical Package for Social Sciences 15.0 (SPSS) and MLWiN. The three levels in the multilevel mixed regression were GPs, participants and measurements, given that participants are nested in GPs, and measurements (at baseline, 25, 47 and 73 weeks after baseline) are nested in participants. The quantitative dependent variables were the number of hours participants were moderately physically active per week, the number of days they engaged in moderate PA, the average daily intake of fruits, the average daily intake of vegetables, the number of days they consumed at least 2 pieces of fruit, the number of days participants consumed at least $200 \mathrm{~g}$ of vegetables, their total fat scores, BMIs, healthrelated quality of life and stage of change. The dichotomous dependent variables assessed whether participants met the public health guidelines measured with a combination of multiple items and one item, as described above. The independent variables were gender, education 
level, hypertension status, age, intervention group, behavioral determinants, whether they received a pedometer as a gift during the intervention period, batch number and region. Due to multiple testing, an alpha of .01 was used to evaluate results.

\section{Process evaluation}

The telephone survey at week 25 and the first follow-up also contained process questions that addressed the quality of the intervention delivery. For TPC, these questions measured, for example, participants' overall satisfaction with the letter, whether they had received and read the letter, and whether the letter was personal, comprehensible and interesting. For TMI, the questions measured, for example, overall satisfaction with the interview, whether the interviewer listened to and understood the participant, whether there was sufficient time to ask questions, and whether the interview was interesting. The competence of the motivational interviewers in MI use was also assessed with the MITI 3.0 and 1-PASS as described above.

\section{Cost-effectiveness analysis}

A cost-effectiveness analysis of Vitalum will be executed if the interventions are found to affect the primary outcome measures [118]. The cost-effectiveness analysis, executed from a healthcare viewpoint, examines the costs and effects of intervention implementation. Direct medical costs involved in carrying out the intervention (e.g., printing and mailing letters for TPC, call charges for TMI) are measured [118]. Other healthcare consumption costs are expected to be equal between the groups and are therefore not part of the analysis. Because Vitalum's goal was to examine the intervention's effectiveness, the developmental costs of the intervention are considered sunk costs and not included in the cost-effectiveness analysis. This also holds for protocol-driven costs (i.e., costs of data gathered as part of a clinical trial [118]); for example, the cost of recording the motivational interviews or that associated with measuring control group participants' behavior and its determinants. Direct non-medical costs (e.g., traveling costs, which were not applicable to Vitalum) and indirect non-medical costs (e.g., productivity costs) are irrelevant given the healthcare perspective chosen.

Since Vitalum may affect both health behavior and health-related quality of life, cost-effectiveness analyses will focus on both levels. To measure cost-effectiveness on a behavioral level, Vitalum's primary outcome measures will be combined into two overall outcome measures: the percentage of improvement in a participant's health behaviors compared to baseline measured using multipleitem measurements; and the number of public health guidelines met by a participant according to the combined measure (0-3: PA, fruit consumption and vegetable consumption). Intervention costs per patient who improved at least $10 \%$ of one health behavior as well as costs per patient who reached a specific number of public health guidelines will be examined. For health-related quality of life, the average improvement in quality of life score (Quality Adjusted Life Years) will be assessed by the RAND 36-item Health Survey $1.0[101,102]$, and intervention costs per patient related to health-related quality of life score will be examined.

\section{Discussion}

This paper described the design of the Vitalum study. Vitalum aims to evaluate the efficacy of TMI and TPC in changing PA and fruit, vegetable and fat intake among Dutch adults aged 45 to 70 . Its strengths are: (a) testing TPC and TMI for multiple behaviors; (b) evaluating TPC versus TMI and both versus TPC+TMI; (c) testing TPC and TMI for people with expected different motivational stages (e.g., participants with and without hypertension); and (d) testing TPC and TMI for people with different education levels.

Vitalum's development was accompanied by practical and operational difficulties. First, although the recruitment of participants via GPs resulted in the required number of participants, this method was time consuming and difficult for both researchers and GPs. GPs had to invest time by providing participant data and excluding certain people; yet, since GPs prioritize patient care and cure and not research, recruitment took more time than planned. Second, the data had to be collected and treated in batches. Combined with the recruitment delay this meant that 18 months lapsed between the enrollment and baseline data collection of the first and last groups. Third, questionnaires with many items were needed to measure and target multiple behaviors and their determinants [25]. This may have increased chances of dropout and invalid data due to participants becoming annoyed [119]. Furthermore, although telephone surveys were planned to reduce dropout risk, they appeared too restrictive and more expensive than paper questionnaires. Thus, paper questionnaires were used to collect baseline and posttest data. To reduce dropout risk, however, we used telephone surveys (at 25 and 39 weeks after baseline) instead of paper questionnaires to gather new data for the computer tailoring interventions. Moreover, although sometimes recommended, we could not use relatively objective reference instruments such as biomarkers for fruit and vegetable consumption $[99,120]$ to validate the self-report questionnaires because they were considered too time consuming and expensive $[67,95]$. We thus used validated self-report questionnaires only $[97,99,100]$. Also, participants were more likely to suffer from hypertension than non-participants. This may be caused by selection bias, in that people with hypertension are more willing to participate than those without. This was confirmed by the fact 
that people who completed the baseline questionnaire were also more likely to suffer from hypertension than people who were excluded or refused to participate. However, this bias may also have been increased by including participants who failed to meet at least two guidelines, since high blood pressure is associated with lack of physical activity and low fruit and vegetable consumption [8]. In addition, the cost-effectiveness analysis does not meet the criteria of a full economic evaluation from a societal perspective; but the cost-effectiveness outcome is not the primary goal of our study. Finally, participants in the TPC group received stage-matched advice based on the stages of change algorithm of the Transtheoretical Model [72]. Although the usefulness and validity of stage models in nutrition and PA research has been criticized $[105,121,122]$, their use in tailoring is still regarded promising [123].

Despite these difficulties, Vitalum aims to generate data on the efficacy of TPC and TMI in changing health behaviors. Its results will help policymakers decide which approach deserves future dissemination; the results on nutrition behavior and PA may also be of value in preventing other risk factors and diseases such as cancer or diabetes $[1,7,8,124]$. Vitalum's results are expected in July 2008.

\section{Competing interests}

The authors declare that they have no competing interests.

\section{Authors' contributions}

HMvK, IM and MA developed and executed the study. KR, MC, JB, GvB, WvM, HS, PJZ and HdV advised on its development and execution. HMvK, IM and MA significantly contributed to writing this paper, while $\mathrm{KR}, \mathrm{MC}, \mathrm{JB}, \mathrm{GvB}$, WvM, HS, PZ and HdV were involved in revising the manuscript. All authors have approved of the version to be published.

\section{Appendix \\ Example of stage-matched tailored PA advice to a contemplator \\ What are your future plans?}

The next part of the letter concerns the future. What plans do you have with regard to physical activity? Do you want to increase or maintain your activity level?

You mentioned in the questionnaire that you have plans to increase your physical activity level to 5 days a week for 30 minutes a day. You also indicated that you want to execute this plan within the next 6 months. This means that you seriously plan to change your activity level. The following information about the advantages of being more physically active may help you in your preparation.
You indicated in the questionnaire seven reasons why increasing your physical activity level would benefit you; that if you are physically active 5 days a week for 30 minutes a day:

- you will consider yourself a better person;

- you will consider yourself a 'sporty' person;

- you will be proud of yourself;

- you will feel younger;

- you may lose weight;

- you will decrease your chances of cardiovascular diseases;

- you will meet new people.

There are good reasons why increasing your level of physical activity is important: your health as well as your physical condition will improve. After 30 years, your muscle and bone strength declines. This is a natural process, but is substantially delayed by being physically active. This means you will be less likely experience bone fractures and will stay lithe.

Other advantages: being physically active positively affects your metabolism and bowel movement, and your risk for cardiovascular diseases and some types of cancer decreases. People who increase their level of physical activity consider themselves better people, are proud of themselves, and feel younger and sportier.

Finally, increasing your physical activity level is also good for your appearance and social contacts. Your chances of meeting people when out walking is higher than when watching a quiz show on television!

You also mentioned two disadvantages of increasing your physical activity level. You indicated that, if you are physically active on at least 5 days a week for 30 minutes a day:

- You run the risk of an injury. If you decide to increase your physical activity level, we recommend that you start easily. Take a break when you become tired - it is not a competition. It is also important that you wear good, solid shoes for walking.

- You will sweat. If you increase your physical activity level, your muscles produce more warmth. This warmth has to be lost to prevent your body temperature getting too high. Fortunately, you lose warmth by sweating; therefore, sweating is absolutely necessary to maintain a healthy 
body temperature. We recommend that you wear clothes with good ventilation when you exercise.

We hope that reading about the positive and possible negative sides of physical activity has reinforced your plans to increase your activity level in the next six months. We conclude this letter with advice that may help you achieve your goal.

First, it is important to choose the type of physical activity that suits you. We asked you in the questionnaire how you might increase your physical activity level. You indicated that:

- You want to use your car less. We often take the car without thinking, for example, to go shopping or to work, though these distances may also be easily walked or cycled.

- You want to take a fast or brisk walk each day. This is a very good idea. If you try to walk at a fixed time each day, this increases the chance that it will become a regular part of your day. By doing this, you can make physical activity a healthy habit.

- You want to be more physically active in your spare time. You may probably have some ideas about this. What one person likes, another might find boring or annoying. This also goes for physical activity. It is therefore important that you choose a type of activity that suits you; otherwise, the chance increases that it will not get past the planning stage, or that you will quit.

\section{Acknowledgements}

This study was funded by The Netherlands Organization for Health

Research and Development (ZonMw, 22000I20).

Vitalum was based on previous studies:

- Computer Tailored Lifestyle Education by Smeets, T., Brug, H. \& de Vries, H. (ZonMw, 22000049);

- Computer Tailored Nutrition Education by Brug, H., van Assema, P., de Vries, H. \& Kok, G. (Dutch Cancer Society);

- Promoting Awareness of Fat, Fruit and Vegetable Intake by Oenema, A. \& Brug, H. (ZonMw, 2100000I);

- Healthy Body Healthy Spirit by Resnicow, K. (National Heart, Lung, and Blood Institute, HL64959);

- North Carolina Strategies to Improve Diet, Exercise, and Screening Study (NC STRIDES) by Campbell, M.K. \& Resnicow, K (National Cancer Institute).

The authors would like to thank:

- the Registry Network of GPs (Registratienetwerk Huisartspraktijken; $\mathrm{RNH}$ ) and the Coordination Institute of Primary Care (Coördinatiebureau
Eerstelijn; CEL) of the Department of General Practice at Maastricht University in the recruitment of GPs;

- the GPs in the recruitment of participants;

- the motivational interviewers for carrying out the interviews;

- the participants for taking part in Vitalum;

- the MEMIC centre for data and information management, for the data entry;

- DD\&H Digital Communication for hosting the computer tailoring program.

\section{References}

I. WHO: Diet, nutrition and the prevention of chronic diseases. In WHO technical report series Geneva, WHO; 2003:I49.

2. Hyson D: The health benefits of fruits and vegetables. A scientific overview for health professionals. Willington, Produce for Better Health Foundation; 2002.

3. Nederlands Huisartsen Genootschap: NGH-Standaard cardiovasculair risicomanagement M84 [Dutch College of General Practitioners (NGH)-Guidelines cardiovascular riskmanagement M84]. 2006:I-26.

4. Graham I, Atar D, Borch-Johnsen K, Boysen G, Burell G, Cifkova R, Dallongeville J, De Backer G, Ebrahim S, Gjelsvik B, Herrmann-Lingen C, Hoes A, Humphries S, Knapton M, Perk J, Priori SG, Pyorala K, Reiner Z, Ruilope L, Sans-Menendez S, Op Reimer WS, Weissberg P, Wood D, Yarnell J, Zamorano JL, Walma E, Fitzgerald T, Cooney MT, Dudina A, Vahanian A, Camm J, De Caterina R, Dean V, Dickstein K, Funck-Brentano C, Filippatos G, Hellemans I, Kristensen SD, McGregor K, Sechtem U, Silber S, Tendera M, Widimsky P, Zamorano JL, Altiner A, Bonora E, Durrington PN, Fagard R, Giampaoli S, Hemingway $\mathrm{H}$, Hakansson J, Kjeldsen SE, Larsen ML, Mancia G, Manolis AJ, Orth-Gomer K, Pedersen T, Rayner M, Ryden L, Sammut M, Schneiderman N, Stalenhoef AF, Tokgozoglu L, Wiklund O, Zampelas A: European guidelines on cardiovascular disease prevention in clinical practice: executive summary. Fourth Joint Task Force of the European Society of Cardiology and other societies on cardiovascular disease prevention in clinical practice (constituted by representatives of nine societies and by invited experts). Eur J Cardiovasc Prev Rehabil 2007, I 4 Suppl 2:EI-40.

5. Lewington S, Clarke R, Qizilbash N, Peto R, Collins R: Age-specific relevance of usual blood pressure to vascular mortality: a meta-analysis of individual data for one million adults in 61 prospective studies. Lancet 2002, 360(9349): $1903-1913$.

6. Jansen M, Van de Vijver L: Fruit and vegetables in chronic disease prevention. Second update. Zoetermeer, Holland Produce Promotion; 2004.

7. USDHHS: Physical activity and health: A report of the surgeon general. Department of Health and Human Services, Centers for Disease Control and Prevention, National Center for Chronic Disease Prevention and Health Promotion, Atlanta; 1996.

8. WHO: The World Health Report 2002. Reducing risks, promoting healthy life. Geneva, WHO; 2002:248.

9. Hu FB, Stampfer MJ, Manson JE, Rimm E, Colditz GA, Rosner BA, Hennekens $\mathrm{CH}$, Willett WC: Dietary fat intake and the risk of coronary heart disease in women. N Engl J Med 1997, 337(2I): | $491-1499$.

10. Gezondheidsraad: Richtlijnen goede voeding 2006 - achtergronddocument [Guidelines for good nutrition 2006 - background document]. Den Haag, Gezondheidsraad; 2006.

II. Kemper HGC, Ooijendijk WTM, Stiggelbout M: Consensus over de Nederlandse norm gezond bewegen [Consensus about the Dutch recommendation for physical activity to promote health]. TSG 2000, 78: 180-183.

12. Krebs-Smith SM, Kantor LS: Choose a variety of fruits and vegetables daily: understanding the complexities. J Nutr 200I, I 3 I (2S-I):487S-50 IS.

13. Pate RR, Pratt M, Blair SN, Haskell WL, Macera CA, Bouchard C, Buchner D, Ettinger W, Heath GW, King AC, et al.: Physical activ- 
ity and public health. A recommendation from the Centers for Disease Control and Prevention and the American College of Sports Medicine. Jama 1995, 273(5):402-407.

14. USDHHSA: Nutrition and your health: dietary guidelines for American. 2005 Dietary guidelines advisory committee report. Department of Health and Human Services and Agriculture; 2005

15. Health Council of the Netherlands: Dietary reference intakes: energy, proteins, fats, and digestible carbohydrates. Den Haag, Health Council of the Netherlands; 200 I.

16. Berrigan D, Dodd K, Troiano RP, Krebs-Smith SM, Barbash RB: Patterns of health behavior in U.S. adults. Prev Med 2003, 36(5):615-623.

17. Fine LJ, Philogene GS, Gramling R, Coups EJ, Sinha S: Prevalence of multiple chronic disease risk factors. 200I National Health Interview Survey. Am J Prev Med 2004, 27(2 Suppl): 18-24.

18. Ford ES, Ford MA, Will JC, Galuska DA, Ballew C: Achieving a healthy lifestyle among United States adults: a long way to go. Ethn Dis 200 I, I I(2):224-23I.

19. Miller RR, Sales AE, Kopjar B, Fihn SD, Bryson CL: Adherence to heart-healthy behaviors in a sample of the U.S. population. Prev Chronic Dis 2005, 2(2):AI8

20. Pronk NP, Anderson LH, Crain AL, Martinson BC, O'Connor P Sherwood NE, Whitebird RR: Meeting recommendations for multiple healthy lifestyle factors. Prevalence, clustering, and predictors among adolescent, adult, and senior health plan members. Am J Prev Med 2004, 27(2 Suppl):25-33.

21. Reeves MJ, Rafferty AP: Healthy lifestyle characteristics among adults in the United States, 2000. Arch Intern Med 2005 , 165(8):854-857.

22. Schuit AJ, van Loon AJ, Tijhuis M, Ocke M: Clustering of lifestyle risk factors in a general adult population. Prev Med 2002, 35(3):219-224.

23. De Vries H, Kremers S, Smeets T, Reubseat A: Clustering of diet, physical activity and smoking and a general willingness to change. Psychol Health 2007:I-I4.

24. Kreuter MW, Skinner CS: Tailoring: what's in a name? Health Educ Res 2000, 15(I): I-4.

25. Brug J, Oenema A, Campbell M: Past, present, and future of computer-tailored nutrition education. Am J Clin Nutr 2003, 77(4 Suppl): I028S-1034S.

26. Campbell MK, James A, Hudson MA, Carr C, Jackson E, Oakes V Demissie S, Farrell D, Tessaro I: Improving multiple behaviors for colorectal cancer prevention among African American church members. Health Psychol 2004, 23(5):492-502

27. Marcus BH, Bock BC, Pinto BM, Forsyth LH, Roberts MB, Traficante RM: Efficacy of an individualized, motivationally-tailored physical activity intervention. Ann Behav Med 1998, 20(3): $174-180$.

28. Vandelanotte C, De Bourdeaudhuij I, Sallis JF, Spittaels H, Brug J: Efficacy of sequential or simultaneous interactive computer-tailored interventions for increasing physical activity and decreasing fat intake. Ann Behav Med 2005, 29(2): I38-I 46.

29. Spittaels H, De Bourdeaudhuij I, Vandelanotte C: Evaluation of a website-delivered computer-tailored intervention for increasing physical activity in the general population. Prev Med 2007, 44(3):209-2I7.

30. Smeets T, Brug J, de Vries $\mathrm{H}$ : Effects of tailoring health messages on physical activity. Health Educ Res 2008, 23(3):402-4I3.

31. Anderson ES, Winett RA, Wojcik JR, Winett SG, Bowden T: A computerized social cognitive intervention for nutrition behavior: direct and mediated effects on fat, fiber, fruits, and vegetables, self-efficacy, and outcome expectations among food shoppers. Ann Behav Med 200I, 23(2):88-100.

32. Baker $\mathrm{AH}$, Wardle J: Increasing fruit and vegetable intake among adults attending colorectal cancer screening: the efficacy of a brief tailored intervention. Cancer Epidemiol Biomarkers Prev 2002, I I (2):203-206.

33. Brug J, Glanz K, Van Assema P, Kok G, van Breukelen G]: The impact of computer-tailored feedback and iterative feedback on fat, fruit, and vegetable intake. Health Educ Behav 1998, 25(4):5|7-53|.

34. Campbell MK, Bernhardt JM, Waldmiller M, Jackson B, Potenziani D Weathers $B$, Demissie $S$ : Varying the message source in computer-tailored nutrition education. Patient Educ Couns 1999, 36(2):157-169.
35. Irvine AB, Ary DV, Grove DA, Gilfillan-Morton L: The effectiveness of an interactive multimedia program to influence eating habits. Health Educ Res 2004, 19(3):290-305.

36. Lutz SF, Ammerman AS, Atwood JR, Campbell MK, DeVellis RF, Rosamond WD: Innovative newsletter interventions improve fruit and vegetable consumption in healthy adults. J Am Diet Assoc 1999, 99(6):705-709.

37. Oenema A, Tan F, Brug J: Short-term efficacy of a web-based computer-tailored nutrition intervention: main effects and mediators. Ann Behav Med 2005, 29(I):54-63.

38. Winett RA, Anderson ES, Bickley PG, Walberg-Rankin J, Moore JF, Leahy M, Harris CE, Gerkin RE: Nutrition for a lifetime system: a multimedia system for altering food supermarket shoppers' purchases to meet nutritional guidelines. Computers in Human Behavior 1997, 13(3):37I-392.

39. Campbell MK, DeVellis BM, Strecher VJ, Ammerman AS, DeVellis RF, Sandler RS: Improving dietary behavior: the effectiveness of tailored messages in primary care settings. Am J Public Health 1994, 84(5): 783-787.

40. De Bourdeaudhuij I, Brug J: Tailoring dietary feedback to reduce fat intake: an intervention at the family level. Health Educ Res 2000, I5(4):449-462.

4I. Kroeze W, Werkman A, Brug J: A systematic review of randomized trials on the effectiveness of computer-tailored education on physical activity and dietary behaviors. Ann Behav Med 2006, 3 I (3):205-223.

42. Miller WR, Rollnick S: Motivational Interviewing: Preparing People for Change. Second edition. New York, The Guilford Press; 2002

43. Sims J, Smith F, Duffy A, Hilton S: Can practice nurses increase physical activity in the over 65s? Methodological considerations from a pilot study. Br J Gen Pract I998, 48(430): I 249- I 250

44. Harland J, White M, Drinkwater C, Chinn D, Farr L, Howel D: The Newcastle exercise project: a randomised controlled trial of methods to promote physical activity in primary care. $\mathrm{Bm}$ 1999, 3 I 9(72 I 3):828-832.

45. Carels RA, Darby L, Cacciapaglia HM, Konrad K, Coit C, Harper J, Kaplar ME, Young K, Baylen CA, Versland A: Using motivational interviewing as a supplement to obesity treatment: a stepped-care approach. Health Psychol 2007, 26(3):369-374.

46. Resnicow K, Campbell MK, Carr C, McCarty F, Wang T, Periasamy S, Rahotep S, Doyle C, Williams A, Stables G: Body and soul. A dietary intervention conducted through African-American churches. Am J Prev Med 2004, 27(2):97-105.

47. Resnicow K, Jackson A, Blissett D, Wang T, McCarty F, Rahotep S, Periasamy S: Results of the healthy body healthy spirit trial. Health Psychol 2005, 24(4):339-348.

48. Resnicow K, Jackson A, Wang T, De AK, McCarty F, Dudley WN, Baranowski T: A motivational interviewing intervention to increase fruit and vegetable intake through Black churches: results of the Eat for Life trial. Am J Public Health 200I, 91(10):1686-1693

49. Mhurchu CN, Margetts BM, Speller V: Randomized clinical tria comparing the effectiveness of two dietary interventions for patients with hyperlipidaemia. Clin Sci (Lond) 1998, 95(4):479-487.

50. Brug J, Spikmans F, Aartsen C, Breedveld B, Bes R, Fereira I: Training dietitians in basic motivational interviewing skills results in changes in their counseling style and in lower saturated fat intakes in their patients. J Nutr Educ Behav 2007, 39(1):8-I2.

5I. Kreuter MW, Bull FC, Clark EM, Oswald DL: Understanding how people process health information: a comparison of tailored and nontailored weight-loss materials. Health Psychol 1999, I8(5):487-494.

52. James AS, Campbell MK, DeVellis B, Reedy J, Carr C, Sandler RS: Health behavior correlates among colon cancer survivors: NC STRIDES baseline results. Am / Health Behav 2006, 30(6):720-730.

53. Campbell MK, Quintiliani LM: Tailored interventions in public health: where does tailoring fit in Interventions to reduce health disparities? Am Behav Sci 2006, 49(6):775-793.

54. Reedy J, Haines PS, Campbell MK: The influence of health behavior clusters on dietary change. Prev Med 2005, 4I (I):268-275.

55. Mackenbach JP, Bos V, Andersen O, Cardano M, Costa G, Harding S, Reid A, Hemstrom O, Valkonen T, Kunst AE: Widening socioeco- 
nomic inequalities in mortality in six Western European countries. Int J Epidemiol 2003, 32(5):830-837.

56. James WP, Nelson M, Ralph A, Leather S: Socioeconomic determinants of health. The contribution of nutrition to inequalities in health. Bmj 1997, 314(7093): I545-1549.

57. Droomers M, Schrijvers CT, van de Mheen H, Mackenbach JP: Educational differences in leisure-time physical inactivity: a descriptive and explanatory study. Soc Sci Med 1998, 47(II): I665-1676.

58. Eurostat: People by age classes. Share of total population (\%). [http://epp.eurostat.ec.europa.eu/ portage? pageid $=1996,39140985 \&$ dad=portal\& schema=POR TAL\&screen $=$ detailref\&language $=$ en\&prod uct $=$ Yearlies new population\&root $=$ Yearlies new population $/ \mathrm{C} /$ $\mathrm{Cl} / \mathrm{Cl}$ I/caal5632].

59. Eurostat: Projected old-age-dependency ratio. [http:p.eurostat.ec.europa.eu/

portage? pageid $=1996,39140985 \&$ dad=portal\& schema $=P O R$ TAL\&screen=detailref\&language $=$ en\&prod uct=REF SD DE\&root=REF SD DE/sd de/sd de cxt/tsdde5II]

60. American College of Sports Medicine Position Stand. Exercise and physical activity for older adults. Med Sci Sports Exerc 1998, 30(6):992-1008

61. Hoeymans N, Hoogenveen RT, Poos MJJC: Ziektelast in DALY's. Oorzaken en gevolgen [Burden of disease in DALY's. Cause and effect]. [http://www.rivm.nl/vtv/object document/ o2879n I 8840.html]

62. Metsemakers JF, Hoppener P, Knottnerus JA, Kocken RJ, Limonard CB: Computerized health information in the Netherlands: a registration network of family practices. Br J Gen Pract 1992, 42(356): $102-106$

63. Van den Akker M, Metsemakers JF, Limonard CB, Knottnerus JA: General Practice: a gold mine for research. Data and scientific use of the Registration Network Family Practices. Maastricht, Unigraphic; 2004.

64. Lamberts H, Wood M: ICPC International Classification of Primary Care. Oxford, Oxford University Press; 1987.

65. Walma EP, Thomas S, Prins A, Grundmeyer HGLM, Van der Laan JR, Wiersma T: NHG - Standaard hypertensie (derde herziening) [Dutch College of General Practitioners (NHG) - Guidelines for hypertension (third revision)]. Huisarts Wet 2003, 46:435-449.

66. Voedingscentrum: Zo eet Nederland 1998. Resultaten van de Voedselconsumptiepeiling 1998 [How the Dutch eat 1998. Results of the food consumption measurement 1998]. Den Haag, Voedingscentrum; 1998.

67. Welk GJ: Physical activity assessments for health-related research. Champaign, Human Kinetics; 2002.

68. Smeets T, Kremers SP, de Vries H, Brug J: Effects of tailored feedback on multiple health behaviors. Ann Behav Med 2007 33(2): $117-123$.

69. De Vries H, Lezwijn J, Hol M, Honing C: Skin cancer prevention: behaviour and motives of Dutch adolescents. Eur J Cancer Prev 2005, I4(I):39-50.

70. De Vries H, Mesters I, van de Steeg H, Honing C: The general public's information needs and perceptions regarding hereditary cancer: an application of the Integrated Change Model. Patient Educ Couns 2005, 56(2): 154- 165.

7I. De Vries H, Mudde A, Leijs I, Charlton A, Vartiainen E, Buijs G, Clemente MP, Storm H, Gonzalez Navarro A, Nebot M, Prins T, Kremers S: The European Smoking Prevention Framework Approach (EFSA): an example of integral prevention. Health Educ Res 2003, 18(5):61 I-626.

72. Prochaska JO, DiClemente CC, Norcross JC: In search of how people change. Applications to addictive behaviors. Am Psychol 1992, 47(9): I I02-III 4

73. De Vries H, Mudde AN, Dijkstra A, Willemsen MC: Differential beliefs, perceived social influences, and self-efficacy expectations among smokers in various motivational phases. Prev Med 1998, 27(5 Pt I):68I-689.

74. Maibach E, Cotton EW: Moving people to behavior change: A staged social cognitive approach in message design. In Designing Health Messages Edited by: Maibach E, Parrott RL. Thousand Oaks, CA, Sage Publications; 1995:4|-64.
75. Carver CS, Scheier MF: Attention and self-regulation: a controltheory approach to human behavior. New York, Springer Verlag; 1981.

76. Resnicow K: I-PASS coding system for motivational interviewing: introduction and scoring. Atlanta, Rollins School of Public Health, Emory University; 2002: I-7.

77. Resnicow K, Jackson A, Braithwaite R, Dilorio C, Blisset D, Rahotep S, Periasamy S: Healthy Body/Healthy Spirit: a church-based nutrition and physical activity intervention. Health Educ Res 2002, 17(5):562-573.

78. Rollnick S, Butler CC, Stott N: Helping smokers make decisions: the enhancement of brief intervention for general medical practice. Patient Educ Couns 1997, 3 I(3): 191-203.

79. Moyers TB, Martin T, Manuel JK, Hendrickson SM, Miller WR: Assessing competence in the use of motivational interviewing. J Subst Abuse Treat 2005, 28(1):19-26.

80. Moyers TB, Martin T, Manual JK, Miller WR, Ernst D: Revised Global Scales: Motivational Interviewing Treatment Integrity 3.0 (MITI 3.0). University of New Mexico, Center on Alcoholism, Substance Abuse and Addictions (CASAA); 2007:28.

8I. Moyers TB, Martin T, Manual JK, Miller WR: The Motivational Interviewing Treatment Integrity (MITI) Code: Version 2.0. Volume 2007. Issue October 18 University of New Mexico, Center on Alcoholism, Substance Abuse and Addictions (CASAA); 2003:19.

82. Rogers RW: A protection motivation theory of fear appeals and attitude change. J Psychol 1975, 91:93-1 |4.

83. Rogers RW: Cognitive and physiological processes in fear appeals and attitude change: a revised theory of protection motivation. In Social psychophysiology: a source book Edited by: Cacioppo JT, Petty RE. New York, Guilford Press; 1983:153-176.

84. Butler C Rollnick S, Cohen D, Bachman M, Russell I, Stott N: Motivational consulting versus brief advice for smokers in general practice: a randomized trial. British Journal of General Practice 1999, 49:61|-616

85. Heather N, Rollnick S, Bell A, Richmond R: Effects of brief counselling among male heavy drinkers identified on general hospital wards. Drug Alcohol Rev 1996, I5(I):29-38.

86. Amanatidis S, Mackerras D, Simpson JM: Comparison of two frequency questionnaires for quantifying fruit and vegetable intake. Public Health Nutr 200 I, 4(2):233-239.

87. Block G, Woods M, Potosky A, Clifford C: Validation of a selfadministered diet history questionnaire using multiple diet records. J Clin Epidemiol 1990, 43( I 2): I 327- 3335.

88. Bogers RP, Dagnelie PC, Westerterp KR, Kester AD, van Klaveren JD, Bast A, van den Brandt PA: Using a correction factor to correct for overreporting in a food-frequency questionnaire does not improve biomarker-assessed validity of estimates for fruit and vegetable consumption. I Nutr 2003, 133(4): $1213-1219$.

89. Kristal AR, Vizenor NC, Patterson RE, Neuhouser ML, Shattuck AL, McLerran D: Precision and bias of food frequency-based measures of fruit and vegetable intakes. Cancer Epidemiol Biomarkers Prev 2000, 9(9):939-944.

90. Sallis JF, Saelens BE: Assessment of physical activity by selfreport: status, limitations, and future directions. Res $Q$ Exerc Sport 2000, 71 (2 Suppl):SI-I4.

91. Serdula M, Byers T, Coates R, Mokdad A, Simoes EJ, Eldridge L: Assessing consumption of high-fat foods: the effect of grouping foods into single questions. Epidemiology 1992, 3(6):503-508

92. Subar AF, Heimendinger J, Patterson BH, Krebs-Smith SM, Pivonka E, Kessler R: Fruit and vegetable intake in the United States: the baseline survey of the Five A Day for Better Health Program. Am J Health Promot 1995, 9(5):352-360.

93. Tionneland A, Overvad K, Haraldsdottir J, Bang S, Ewertz M, Jensen $O M$ : Validation of a semiquantitative food frequency questionnaire developed in Denmark. Int J Epidemiol 1991, 20(4):906-912

94. Urlings IJM, Douwes M, Hildebrandt VH, Stiggelbout M, Ooijendijk WTM: Relatieve validiteit van een vragenlijst naar lichamelijke activiteit volgens de 'beweegnorm' [Relative validity of a questionnaire to measure physical activity according to the 'physical activity recommendation']. Geneesk Sport 2000 , 33(4): 17-22.

95. Van Assema P, Brug J, Ronda G, Steenhuis I, Oenema A: A short Dutch questionnaire to measure fruit and vegetable intake: 
relative validity among adults and adolescents. Nutr Health 2002, I6(2):85-106.

96. Wendel-Vos GC, Schuit AJ, Saris WH, Kromhout D: Reproducibility and relative validity of the short questionnaire to assess health-enhancing physical activity. J Clin Epidemiol 2003, 56(I2): I 163-1169.

97. Resnicow K, McCarty F, Blissett D, Wang T, Heitzler C, Lee RE: Validity of a modified CHAMPS physical activity questionnaire among African-Americans. Med Sci Sports Exerc 2003 35(9): $1537-1545$

98. Ainsworth BE, Haskell WL, Whitt MC, Irwin ML, Swartz AM, Strath SJ, O'Brien WL, Bassett DR Jr., Schmitz KH, Emplaincourt PO, Jacobs DR Jr., Leon AS: Compendium of physical activities: an update of activity codes and MET intensities. Med Sci Sports Exerc 2000, 32(9 Suppl):S498-504.

99. Bogers RP, Van Assema P, Kester AD, Westerterp KR, Dagnelie PC: Reproducibility, validity, and responsiveness to change of a short questionnaire for measuring fruit and vegetable intake. Am J Epidemiol 2004, 159(9):900-909.

100. Van Assema P, Brug J, Ronda G, Steenhuis I: The relative validity of a short Dutch questionnaire as a means to categorize adults and adolescents to total and saturated fat intake. J Hum Nutr Diet 200I, I4(5):377-390.

I0I. Brazier JE, Harper R, Jones NM, O'Cathain A, Thomas KJ, Usherwood $T$, Westlake L: Validating the SF-36 health survey questionnaire: new outcome measure for primary care. Bmj 1992 305(6846): $160-164$

102. Van der Zee KI, Sanderman R: Het meten van de algemene gezondheidstoestand met de RAND-36. Een handleiding [Measuring general health with the RAND-36. A manual]. Groningen , Noordelijk Centrum voor Gezondheidsvraagstukken. Rijksuniversiteit Groningen; 1993: I-28.

103. Armitage CJ, Arden MA: Exploring discontinuity patterns in the transtheoretical model: An application of the theory of planned behaviour. BrJ Health Psychol 2002, 7(Pt I):89-103.

104. Laforge RG, Velicer WF, Richmond RL, Owen N: Stage distributions for five health behaviors in the United States and Australia. Prev Med 1999, 28(I):6I-74.

105. de Vet E, de Nooijer J, de Vries NK, Brug J: Determinants of forward stage transition from precontemplation and contemplation for fruit consumption. Am J Health Promot 2005, 19(4):278-285.

106. De Vries H, Kremers S, Smeets T, Brug J, Eijmael K: The effectiveness of tailored feedback and action plans in an intervention addressing multiple health behaviors. Am J Health Promot in press.

107. Verplanken B, Orbell S: Reflections on past behavior: a selfreport index of habit strength. Journal of Applied Social Psychology 2003, 33(6): $1313-1330$

108. Brug J, Van Assema P, Kok G, Lendering T, Glanz K: Self-rated dietary fat intake: association with objective assessment of fat, psychosocial factors, and intention to change. I Nutr Educ 1994, 26(5):218-223.

109. Ronda G, Van Assema P, Brug J: Stages of change, psychological factors and awareness of physical activity levels in The Netherlands. Health Promot Int 200I, 16(4):305-3/4

110. Mudde AN, Willemsen MC, Kremers S, Vries H: Meetinstrumenten voor onderzoek voor roken en stoppen met roken [Measures for research with regard to smoking behavior or smoking cessation]. Den Haag, Stivoro; 2000.

III. Lemmens P, Tan ES, Knibbe RA: Measuring quantity and frequency of drinking in a general population survey: a comparison of five indices. J Stud Alcohol I 992, 53(5):476-486.

1 12. Corbin CB, Welk G], Corbin WR, Welk KA: Concepts of Physical Fitness. Active Lifestyles for Wellness. 12th edition. New York , McGraw-Hill; 2004.

113. Thomas S, Reading J, Shephard RJ: Revision of the Physical Activity Readiness Questionnaire (PAR-Q). Can J Sport Sci 1992, I7(4):338-345.

I 14. Kirkwood BR: Essentials of medical statistics. Oxford, Blackwel Scientific Publications; 1988:234.

I I5. Cohen J: Statistical power analysis for the behavioral sciences. 2nd edition. Hillsdale, NJ, Lawrence Erlbaum; 1988.

116. Moerbeek M, van Breukelen GJ, Berger MP: A comparison between traditional methods and multilevel regression for the analysis of multicenter intervention studies. / Clin Epidemiol 2003, 56(4):34I-350.

II7. Senn SJ: The use of baselines in clinical trials of bronchodilators. Stat Med I989, 8(II):1339-1350.

I 8. Drummond MF, O'Brien BJ, Stoddard GL, Torrance GW: Methods for the Economic Evaluation of Health Care Programmes. Second edition. New York, Oxford University Press; 1997.

119. Kremers SP, Visscher TL, Seidell JC, van Mechelen W, Brug J: Cognitive determinants of energy balance-related behaviours: measurement issues. Sports Med 2005, 35( I I):923-933.

120. Resnicow K, Odom E, Wang T, Dudley WN, Mitchell D, Vaughan R, Jackson A, Baranowski T: Validation of three food frequency questionnaires and 24-hour recalls with serum carotenoid levels in a sample of African-American adults. Am J Epidemiol 2000, I52(I I): 1072-1080.

121. Adams J, White M: Why don't stage-based activity promotion interventions work? Health Educ Res 2005, 20(2):237-243.

122. De Vet E, de Nooijer J, de Vries NK, Brug J: The Transtheoretical model for fruit, vegetable and fish consumption: associations between intakes, stages of change and stage transition determinants. Int J Behav Nutr Phys Act 2006, 3:13

123. Brug J, Conner M, Harre N, Kremers S, McKellar S, Whitelaw S: The Transtheoretical Model and stages of change: a critique: observations by five commentators on the paper by Adams, J. and White, M. (2004) why don't stage-based activity promotion interventions work? Health Educ Res 2005, 20(2):244-258.

124. World Cancer Research Fund: Food, nutrition and the prevention of cancer: A global perspective. Washington, World Cancer Research Fund and American Institute for Cancer Research; 1997.

125. European Commission: Task force on core social variables. Final report. Luxembourg, Office for Official Publications of the European Communities; 2007:127.

126. Ministerie van Onderwijs Cultuur en Wetenschappen: Onderwijsprofiel van Nederland [Education profile of the Netherlands]. Den Haag, Ministerie van Onderwijs, Cultuur en Wetenschappen; 2003:20.

127. United Nations Educational Scientific and Cultural Organization: International Standard Classification of Education, ISCED 1997. Paris, United Nations Educational Scientific and Cultural Organization (UNESCO); 1997:42.

\section{Pre-publication history}

The pre-publication history for this paper can be accessed here:

\section{http://www.biomedcentral.com/1471-2458/8/216/pre pub}

Publish with Bio Med Central and every scientist can read your work free of charge

"BioMed Central will be the most significant development for disseminating the results of biomedical research in our lifetime. "

Sir Paul Nurse, Cancer Research UK

Your research papers will be:

- available free of charge to the entire biomedical community

- peer reviewed and published immediately upon acceptance

- cited in PubMed and archived on PubMed Central

- yours - you keep the copyright
BiolMedcentral 